\title{
Inter-ethnic variations in association of TNF-alpha g308a single nucleotide polymorphism with type 2 diabetes mellitus-a review
}

\begin{abstract}
Summary
According to World Health Organization, the prevalence of diabetes mellitus (DM) is on the rise. Tissue necrosis factor- alpha (TNF- $\alpha$ ) is one of the inflammatory markers which play role in the pathogenesis of DM. Single nucleotide polymorphism (SNP) at 308G/A has been reported to be associated with type 2 DM. Frequency of TNF- $\alpha$ G308A polymorphism was determined in different ethnic groups and is found to be highly variable. Limited number of studies reported a positive association between type 2 DM and TNF- $\alpha$ SNP and many studies; including meta-analyses failed to find such association. TNF- $\alpha$ G308A polymorphism has been found to be associated with insulin resistance and BMI, although these findings are challenged by many studies. The probable explanation of higher BMI is the association of presence of TNF- $\alpha$ G308A polymorphism with higher rates of lipid synthesis, and suppression of FFA levels in obese persons. There is no single explanation for such highly variable results in different ethnic groups. Presence of yet unidentified gene polymorphism in linkage disequilibrium with TNF- $\alpha$ gene polymorphism could be responsible. The different results can also be contributed to the fact that the study groups differ in age, gender distribution, age of onset of disease, life style, degree of obesity and glucose tolerance. Comprehensive genetic studies of whole TNF-alpha promoter area are required to be done in large population samples in different ethnic groups. Polymorphisms are usually co-related in a complex manner and are co-inherited and conclusions are difficult to be drawn on small sample size.
\end{abstract}

Keywords: tissue necrosis factor alpha, diabetes mellitus; world health organization, polymorphisms, diabetes mellitus, metabolism, insulin, TNF- $\alpha$, patients, type $2 \mathrm{dm}$
Volume 4 Issue 2 - 2017

\author{
Amina Nadeem,' Sadaf Mumtaz, ${ }^{2}$ Abdul \\ Khaliq Naveed ${ }^{3}$ \\ 'National University of Medical Sciences, Pakistan \\ 'University of Dammam, Saudi Arabia \\ ${ }^{3}$ Rifah University, Pakistan
}

Correspondence: Amina Nadeem, Army Medical College, National University of Medical Sciences, Rawalpindi, Pakistan, Tel +92333523 1806, Email nadeemamina@yahoo.com

Received: July 19,2016 | Published: March 09, 2017

\section{Introduction}

According to World Health Organization (WHO) and International Diabetes Foundation, the prevalence of diabetes mellitus (DM) is on the rise. It was 100-135million individuals worldwide in 19941995 , increased to 171 million in 2000 approximately 246 million in 2007 and 289 million (6.4\%) in $2010 .{ }^{1}$ The prevalence is expected to increase up to 439 million (7.7\%) by the year $2030 .{ }^{2}$ Diabetes mellitus is a metabolic disorder of multiple etiologies characterized by chronic hyperglycemia with disturbances of carbohydrate, fat and protein metabolism resulting from defects from insulin secretion, insulin action, or both. Inflammatory markers play role in pathogenesis of type 2 DM. G308A promoter single nucleotide polymorphism (SNP) of TNF- $\alpha$ gene was found to be associated with type 2 diabetes mellitus. TNF- $\alpha$ G308A polymorphisms also associated with serum TNF- $\alpha$ levels, insulin resistance, insulin levels, body mass index, and lipid profile. There is inter- ethnic variations; not only in the frequency of this polymorphism in type 2 diabetics and healthy populations but also in association with type $2 \mathrm{DM}$, serum TNF- $\alpha$ levels, insulin resistance, body mass index, and lipid profile, reported in international studies. The present review analyzes these inter-ethnic variations and determines possible causes of these variations. A total of 45 full text articles on the subject conducted from 1995-2012, found on electronic sources were reviewed.

\section{Role of inflammation in pathogenesis of $\mathrm{dm}$}

The rapid increase in type $2 \mathrm{DM}$ incidence in last decade indicates significant role of environmental and dietary factors in addition to genetic factors. Obesity is strongly associated with type $2 \mathrm{DM}$. Obesity is considered as chronic low grade inflammatory state and markers of sub clinical inflammation increase in the blood of type 2 DM patients many years before diagnosis of the disease. ${ }^{3}$ These markers play a considerable role in pathogenesis of type $2 \mathrm{DM}$, obesity, insulin resistance and apoptosis of beta cells of endocrine pancreas and include interleukin-6 (IL-6), IL-1, IL-18, TNF- $\alpha$, C-reactive protein (CRP), tissue plasminogen activator (TPA), heptoglobulin and fibrinogen. ${ }^{3}$

\section{TNF-alpha}

TNF- $\alpha$ has multiple mechanisms. It stimulates IL- 6 release and directly inhibits insulin signaling by phosphorylation at serine 307 residue of IRS-1. It also induces transcription factor nuclear factor (NF)-kappa B which causes apoptosis of beta cell of pancreas. TNF- $\alpha$ also increases elevated serum free fatty acids (FFA) levels. ${ }^{4}$ Local inflammation in obese adipose tissue was first reported in $2003 .{ }^{1}$ Elevated serum levels of TNF- $\alpha$ are found in type 2 DM patients and in obese healthy persons who subsequently developed type $2 \mathrm{DM}$ in a span of 2-4 years indicating the future risk of metabolic syndrome and type $2 \mathrm{DM}^{3,5-7}$ Adipocytes contribute almost all of TNF- $\alpha$ and explain the association of high TNF- $\alpha$ level with obesity and raised body mass index. ${ }^{7,8}$ Indirect studies also indicate exercise and weight loss can lead to decreased concentration of TNF- $\alpha .{ }^{7,9}$ High levels of TNF- $\alpha$ have been reported to be associated with insulin resistance. ${ }^{9-11}$ 
TNF $\alpha$ renders insulin resistance by interfering with insulin signaling in adipocytes and hepatocytes. TNF- $\alpha$ causes insulin resistance in skeletal muscle too by impairing glucose uptake and translocation of glucose uptake transporters (GLUT-4). ${ }^{12}$ Hyperinsulinemia itself induces augmented production of TNF- $\alpha$ in serum in obese type 2 DM patients. ${ }^{9-13}$ High glucose uptake results in apoptosis of beta cells in pancreas with increase expression of IL-1 B messenger ribonucleic acid (mRNA) and its levels. IL-1B pro apoptotic effects are found to be mediated by augmenting IL- $6 .{ }^{14}$ TNF- $\alpha$ also has pro-apoptotic effect by activation of transcription factor nuclear factor (NF)-kappa B target genes in cultured beta cells of pancreas. ${ }^{15}$

\section{TNF-alpha single nucleotide polymorphism}

TNF- $\alpha$ gene is located on 21.3 locus on short arm of chromosome number 6 (6p 21.3), span about $3 \mathrm{~kb}$ and contains 4 exons. The gene lies in the class III region of major histo compatibility complex (MHC), 250kilobases centromeric of the HLA-B locus and 850 kilobasestelomeric of HLA-DR. The gene codes for TNF- $\alpha$ as 157 amino acid polypeptide processed from 233 amino acid precursor. The -308 A allele of TNF- $\alpha$ lies on the extended haplotype HLA-A1B8-DR3-DQ2. ${ }^{16}$ The frequency of TNF- $\alpha-308$ A allele was found to be variable in different ethnic groups (Table 1) (Table 2).

Table I Frequency of TNF-Alpha G308A Polymorphism in Different Ethnic Groups

\begin{tabular}{|c|c|c|c|c|c|c|}
\hline \multirow{2}{*}{ S. No. } & \multirow{2}{*}{ Ethnic group } & \multirow{2}{*}{$\mathbf{N}$} & \multicolumn{3}{|c|}{ TNF-alpha genotype } & \multirow{2}{*}{ Reference } \\
\hline & & & GG(\%) & GA(\%) & AA(\%) & \\
\hline \multirow{2}{*}{ I } & Obese Asian Indian & 201 & 90.5 & 9.5 & nil & \multirow{2}{*}{ Bhagat et al. ${ }^{35}$} \\
\hline & Non-obese Asian Indians & 143 & 95.1 & $4.90 \%$ & nil & \\
\hline \multirow{2}{*}{2} & Diabetic South Indians & 330 & 10.6 & 86.4 & 3 & \multirow{2}{*}{ Kolla et al. ${ }^{34}$} \\
\hline & Healthy South Indians & 250 & 2 & 94 & 4 & \\
\hline 3 & Spanish & 313 & 86 & & 14 & Carbalan et al. ${ }^{57}$ \\
\hline 4 & Obese Polish & 121 & 52.89 & 46.28 & 0.8 & Wybranska et a. ${ }^{43}$ \\
\hline 5 & Finnish & 490 & 74 & 25 & 1 & Kubaszek et al. ${ }^{17}$ \\
\hline 6 & Australian & 170 & 31 & 64 & 5 & Morris at al. ${ }^{31}$ \\
\hline 7 & Healthy Taiwanese & 246 & 84.2 & 15.4 & 0.4 & Sheu et al. ${ }^{41}$ \\
\hline 8 & Obese Australian & 180 & 76 & 24 & & Dalziel et al. ${ }^{45}$ \\
\hline 9 & Germens & 176 & 67 & 30 & 2.84 & Brand et al..$^{55}$ \\
\hline \multirow{2}{*}{10} & Obese Romans & 115 & 86.9 & & 13.1 & \multirow{2}{*}{ Romeo et al. ${ }^{51}$} \\
\hline & Lean Romans & 79 & 85.4 & & 14.6 & \\
\hline \multirow{2}{*}{ II } & Healthy Hong Kong Chinese & $|2|$ & 92.6 & 7.4 & & \multirow{2}{*}{ Lee et al..$^{50}$} \\
\hline & Diabetic Hong Kong Chinese & 440 & 91 & 9 & & \\
\hline \multirow{3}{*}{12} & Young healthy Japanese & 122 & 96.7 & & 3.3 & \multirow{3}{*}{ Ishii et al..$^{58}$} \\
\hline & Old healthy Japanese & 177 & 97.2 & & 2.8 & \\
\hline & Diabetic Japanese & 177 & 97.2 & & 2.8 & \\
\hline 13 & Healthy French & \multirow{2}{*}{710} & 85 & & 15 & \multirow{2}{*}{ Hermann et al. ${ }^{54}$} \\
\hline 14 & Belfast & & 76 & & 24 & \\
\hline 15 & Healthy Belgarians & 62 & 66 & 25.8 & 8 & Louis et al. ${ }^{38}$ \\
\hline
\end{tabular}

Table 2 Inter-Ethnic Variations in Frequency of TNF-Alpha -308A Allele

\begin{tabular}{lcl}
\hline Ethnic group & TNF- alpha $\mathbf{- 3 0 8}$ A allele(\%) & Reference \\
\hline Diabetic Japanese & 2.2 & Yamashina et al. ${ }^{18}$ \\
\hline Caucasian Whites & 45 & \\
Healthy Finnish & 36 & \\
Healthy Brazilians & 23 & Sookoin et al. ${ }^{16}$ \\
Healthy Chinese & 18 & \\
Healthy Japanese & 3 & \\
\hline
\end{tabular}




\begin{tabular}{lll} 
Table continued... & TNF- alpha -308 A allele(\%) & Reference \\
\hline Ethnic group & 24.2 & \\
\hline Healthy Irelanders & 15.8 & \\
Healthy Swedish & 8.7 & Wang et al. ${ }^{39}$ \\
Diabetic Chinese & 7.4 & \\
Non-diabetic Chinese & 1.5 & \\
Non-diabetic Japanese & 1.4 & \\
Diabetic Japanese & 35 & Li et al. $^{23}$ \\
Diabetic Swedish & 33 & Rasmussen et al. ${ }^{30}$ \\
Healthy Swedish & 18.9 & Fernandez-Real et al. \\
Danish \& Spanish & 19 & Wilson et al. ${ }^{36}$ \\
White \& African Americans, British & 19 &
\end{tabular}

\section{TNF-alpha G308A polymorphism and type $\mathbf{2} \mathrm{dm}$}

Association of TNF- $\alpha$ G308A allele with pathogenesis of type $2 \mathrm{DM}$ is explained by the fact that $-308 \mathrm{~A}$ allele is responsible for increased transcription of TNF- $\alpha$ as compared to $-308 \mathrm{G}$ allele as high as two folds leading to increased serum levels of TNF- $\alpha .{ }^{17}$ High levels of TNF- $\alpha$ play its role in the pathogenesis of type 2 DM by the mechanisms mentioned above. Genetic studies on association of TNF- $\alpha$ G308A polymorphism with type 2 DM, serum TNF- $\alpha$ levels, insulin resistance and obesity however, reveal conflicting results. Association between TNF- $\alpha$ G308A with type $2 \mathrm{DM}$ has been found to be positive in Japanese and in older diabetic subjects from Netherlands. ${ }^{18}$ In these individuals, risk of type 2 DM was 4.6 folds higher in homozygous 308AA allele and 0.9 folds higher in 308GA allele. The risk estimate for AA genotype was 6.5 among men and 3.0 among women. ${ }^{19}$ Risk of type $2 \mathrm{DM}$ was found to be increased by two folds by $-308 \mathrm{~A}$ allele in Finnish population. In fact, $12.6 \%$ of overweight IGT subjects with $308 \mathrm{GG}$ and $20.7 \%$ of subjects with 308A allele developed type 2 DM. ${ }^{20}$

No significant association was found in type 2 DM and TNF- $\alpha$ G308A polymorphism in diabetic Americans, ${ }^{21}$ Greeks, ${ }^{22}$ Swedes,${ }^{23}$ Chinese, ${ }^{24,25}$ Koreans, ${ }^{26}$ British, ${ }^{27}$ Taiwanese, ${ }^{28}$ Japanese, ${ }^{29}$ Danish Caucasians ${ }^{30}$ and in obese Australians. ${ }^{31}$ In a recent study on Tunisian population, TNF- $\alpha$ SNP was not found to be associated with type 2 DM. ${ }^{32}$ In a meta-analysis of 18 studies; comprising of 7611 type 2 DM and 6944 healthy controls, no association was found between TNF- $\alpha$ G308A polymorphism and DM. ${ }^{33}$ The frequency of TNF- $\alpha$ genotypes in South Indian diabetic patients was found to be GG $10.6 \%$, GA $86.4 \%$ and AA in $3 \%$ while in healthy controls, it was GG $2 \%$, GA $94.5 \%$ and AA $4 \%,{ }^{34}$ indicating no significant association of DM and polymorphism. In another study, on obese and non-obese healthy Indian Asians, GA genotype was found to be $9.5 \%$ and $4.9 \%$ respectively. ${ }^{35}$

\section{TNF-alpha G308A polymorphism and serum TNF- alpha levels}

Production of TNF- $\alpha$ is regulated at transcription, posttranscription and translation levels. In response to various stimuli like lipopolysaccharides (LPS) stimulation of macrophages, TNF transcription increases 3 folds TNF mRNA increases to as high as 100 folds. This leads to synthesis of TNF- $\alpha$ increased by a factor of $\sim 10,000$ at translation level. ${ }^{36}$ Slight change at transcription level can markedly change the serum levels of TNF- $\alpha$. The role of TNF- $\alpha$ G308A polymorphism as a much stronger transcriptional activator and its association with increased serum TNF- $\alpha$ levels was first described in 1997 in human B cell line. Wilson et al. ${ }^{36}$ demonstrated that there was no difference in the affinity of DNA-binding proteins between $\mathrm{G}$ and $\mathrm{A}$ allele, indicating direct effect of polymorphism on gene regulation where as in another study, it was demonstrated in cell cultures that TNF- $\alpha$ 308A allele leads to greater affinity of nuclear factor to promoter area resulting in two fold increase in transcription and ultimately higher serum levels. ${ }^{37}$ Similarly, LPS stimulated release of TNF- $\alpha$ in whole blood cell culture was found to be augmented in the presence of 308A allele. ${ }^{38} \mathrm{TNF}-\alpha$ 308A allele was found to be associated with higher reporter gene activity and also increased TNF- $\alpha$ production in whole blood cell cultures. ${ }^{19}$ TNF- $\alpha$ $308 \mathrm{~A}$ allele was found to augment the TNF- $\alpha$ transcription, increased TNF mRNA in adipose tissues and increased serum TNF- $\alpha$ levels; leading to increased susceptibility to type $2 \mathrm{DM}$. Serum TNF- $\alpha$ levels in TNF- $\alpha-308 \mathrm{~A}$ allele carriers were found to be increased 2 folds in overweight Finnish subjects, ${ }^{20}$ in Danish Caucasians, ${ }^{30}$ in Chinese $^{39}$ and in American females ${ }^{9}$ The difference in S. TNF- $\alpha$ levels based on genotype was observed neither in healthy controls, impaired glucose tolerant and diabetic Czech Caucasians ${ }^{40}$ nor in healthy Chinese. ${ }^{41}$

\section{TNF-alpha G308A polymorphism and insulin resistance}

Association between G308A polymorphism and insulin resistance again show variable results although higher levels of TNF- $\alpha$ in $-308 \mathrm{~A}$ allele carrying subjects is expected to cause increased insulin resistance. The association was found to be positive in obese middleaged male and female Spanish subjects; more marked in females and serum insulin levels were higher in both $-308 \mathrm{GA}$ and AA allele carriers, ${ }^{42}$ in obese female Polish Caucasians ${ }^{43}$ and in diabetic obese Canadian patients, but not in non-obese diabetic Canadians. ${ }^{44}$ Positive association between $308 \mathrm{~A}$ allele and insulin resistance was also found in obese Australians. ${ }^{45}$ There was also strong negative association between $308 \mathrm{~A}$ allele and S. HDL-cholesterol, although 
insulin resistance was positively associated with BMI and waist circumference (WC) in all obese irrespective of G or A allele in obese Australians. ${ }^{45}$ No significant differences by polymorphism carrier status were found for insulin resistance in Australian females, ${ }^{46}$ in diabetic Japanese patients, ${ }^{29,47}$ in Danish Caucasians, ${ }^{30}$ in obese Americans ${ }^{48}$ in young healthy relatives of type 2 diabetic German Caucasians ${ }^{49}$ in Hong Kong Chinese,${ }^{50}$ in obese and lean Romans ${ }^{51}$ and in overweight IGT Finnish subjects. ${ }^{20}$ This association was neither found in relatives of type 2 diabetic British Caucasians and in controls ${ }^{52}$ nor in type 2 diabetic subjects from New England..$^{21}$ In healthy Chinese, no difference in insulin resistance based on allele frequency was found. ${ }^{41}$

\section{TNF-alpha G308A polymorphism and bmi}

TNF- $\alpha 308 \mathrm{G} / \mathrm{A}$ polymorphism has been found to be associated with higher BMI, although this finding is challenged by many studies. The probable explanation of higher $\mathrm{BMI}$ is the association of presence of TNF- $\alpha$ G308A polymorphism with higher rates of lipid synthesis, and suppression of FFA levels in obese persons but not in non-obese healthy persons. Interestingly, TNF- $\alpha$ a allele was associated with augmented glucose oxidation in non-obese healthy subjects but not in obese subjects. ${ }^{53}$ This indicates the differential effect of TNF- $\alpha$ -308 A allele on lipid and glucose metabolism in obese and non-obese subjects.

Association between TNF- $\alpha$ G308A polymorphism with obesity has been found in obese diabetic and non-diabetic French and Irish subjects than those controls with $308 \mathrm{G}$ allele. ${ }^{54}$ This positive association was also found in obese Spanish population, ${ }^{42}$ in male Polish Caucasians ${ }^{43}$ in Germens ${ }^{55}$ and in obese Swedish females with AA genotype. ${ }^{56} 308 \mathrm{~A}$ allele showed a 23 percent increased risk of obesity in a meta- analysis of 3562 individuals from 08 studies. 16 TNF- $\alpha$ allele was found to be associated with higher BMI, waist and hip circumference and total body fat in obese Spanish Caucasians. ${ }^{57}$ However, 308A allele was not associated with obesity in Australian females, ${ }^{46}$ in diabetic and non-diabetic subjects from New England, ${ }^{21}$ in obese Caucasians and African Americans, ${ }^{48}$ in diabetic Japanese, ${ }^{58}$ in obese Chinese, ${ }^{39}$ in elderly Chilean women,,${ }^{59}$ in healthy Tunisians, ${ }^{60}$ in obese and lean Romans ${ }^{51}$ and in obese Australians. ${ }^{31}$ TNF- $\alpha-308 \mathrm{~A}$ allele did not affect the amount of weight loss in male and female Danish Caucasians in another study. ${ }^{30}$

The association between TNF- $\alpha-308$ heterozygous GA with higher S. FFA levels as compared to GG genotype has been found in Chinese non-diabetics ${ }^{33}$ although in another study, A allele was associated with higher lipid synthesis and suppressed FFA levels in over-weight Finnish subjects though, the same allele was associated with higher glucose oxidation but not with higher lipid synthesis or suppressed FFA levels in non-obese healthy Finnish subjects. ${ }^{53}$ Percent body fat was found to be increased in the presence of A allele in obese Spanish population ${ }^{42}$ whereas Obese Chinese with GG genotype had lower HDL cholesterol than carriers of GA or AA genotype. ${ }^{39}$ TNF- $\alpha$ a allele was not associated with BMI or lipid profile in Hong Kong Chinese with metabolic syndrome in another study. ${ }^{50}$ In older, but not in young diabetic Japanese men, TNF polymorphism was found to be associated with higher TG and lower HDL levels. ${ }^{58}$ In overweight IGT Finnish subjects, simultaneous polymorphism in IL6 G174C and TNF- $\alpha$ G308A showed a 2.2 fold increase risk of type 2 DM than neither of SNP, although risk was not higher in simultaneous SNP's as compared to $308 \mathrm{~A}$ SNP alone. ${ }^{20}$

\section{Possible reasons for varying results in association of TNF-alpha G308A SNP with type 2 DM inter-ethnically}

The underlying reasons for conflicting results in different ethnic groups regarding association between TNF-alpha G308A polymorphism with type 2 diabetes mellitus, serum TNF- $\alpha$ levels, insulin resistance and BMI in diabetic, IGT and healthy subjects are not fully known. Association of TNF- $\alpha-308$ G/A polymorphism with diabetes mellitus and insulin resistance show inconsistent results. One explanation for association of this SNP with DM is increased insulin resistance caused by raised serum levels of TNF- $\alpha$. The fact that TNF- $\alpha$ a allele leads to augmented transcription and higher serum levels is very strongly supported by in vitro studies on cell culture, cell lines and on animal models. Production of TNF- $\alpha$ is regulated at transcription, post-transcription and translation levels. In response to various stimuli like lipopolysaccharides stimulation of macrophages, TNF transcription increases 3-folds, TNF mRNA increases to as high as 100 folds. This leads to synthesis of TNF- $\alpha$ increased by a factor of $\sim 10,000$ at translation level. ${ }^{36}$ Slight change at transcription level can markedly change the serum levels of TNF- $\alpha$. The presence of a allele at 308 position is one of those factors which augments the transcription and ultimately translation, thus resulting in higher serum levels of TNF- $\alpha$.

Despite quite large number of studies on association of DM with this SNP, insulin resistance and BMI; very few studies correlated the serum levels of TNF with insulin resistance, BMI or risk of DM. Association of A allele with higher serum levels of TNF has been reported in overweight Finnish subjects, ${ }^{20}$ in Danish Caucasians,${ }^{30}$ in Chinese ${ }^{39}$ and in American females. ${ }^{9}$ Negative association has been reported in healthy controls, impaired glucose tolerant and diabetic Czech Caucasians ${ }^{40}$ and in healthy Chinese. ${ }^{41}$ It is well documented that insulin resistance is associated with BMI but when catering for genotypes, A allele association with insulin resistance in presence of obesity but not in absence of it, has been reported in diabetic Canadians. ${ }^{44}$ Interestingly not many studies were found in literature indicating positive association of a allele presence with higher insulin resistance even in absence of obesity. In one study, insulin resistance was found greater in both obese and lean Romans ${ }^{51}$ in either allele carriers. It may indicate the possibility that insulin resistance may be secondary to raised BMI, in all obese irrespective of genotype; the fact supported by studies on obese Australian, ${ }^{44}$ obese Americans, ${ }^{48}$ overweight IGT Finnish subjects ${ }^{20}$ and obese female Polish Caucasians ${ }^{43}$ in which insulin resistance was present in obese subjects carrying either allele. TNF- $\alpha$ polymorphism may act as a genetic factor enhancing the insulin resistance in presence of obesity, irrespective of serum TNF- $\alpha$ level as found in many studies. Why in some studies, this association between polymorphism and insulin resistance is not found even in presence of obesity is not known.

Variable results regarding TNF- $\alpha$ SNP at -308 in different ethnic groups might be due to yet another unidentified functional gene polymorphism in close linkage disequilibrium with TNF- $\alpha$ G308A polymorphism. In support of this hypothesis, an association between B-9 allele of AG/GT dinucleotide repeat polymorphism of TNF- $\alpha$ gene and diabetic retinopathy in Southern Indian population has been reported. ${ }^{61}$ Similarly, polymorphism of a stress protein gene; P2/P2 genotypes of heat shock protein $70-2$ is found to be close to and in linkage disequilibrium with TNF- $\alpha$ promoter area and is statistically associated with obesity in Tunisian subjects. ${ }^{60}$ 
Contribution of other, yet unidentified DM susceptibility genes in insulin resistance and beta cell failure is also being explored. Proinflammatory and anti-inflammatory cytokines interact with each other and play role in altering beta cell functions and TNF- $\alpha$ gene may influence this interaction. Moreover, there could be additional, still unidentified risk factors which obscure the impact of SNP with specific genetic background in various ethnic groups. The life style and average age of onset of DM in different ethnic groups may affect the impact of polymorphism in susceptibility of the disease. The different results can also be contributed to the fact that the study groups differ in age, gender distribution, life style, degree of obesity and glucose tolerance. Single nucleotide polymorphism may be considered as a susceptibility factor in certain population segments based on other risk factors and comprehensive studies with large number of sample size may indeed be required to statistically manifest SNPrelated risk factors. Most of the studies are done in relatively small population groups which might include patient selection biases and do not reflect the general risk of population. Comprehensive genetic studies of whole TNF-alpha promoter area are required to be done in large population samples in different ethnic groups. Polymorphisms are usually co-related in a complex manner and are co-inherited and conclusions are difficult to be drawn on small sample size.

\section{Acknowledgements}

None.

\section{Conflict of interest}

Author declares that there is no conflict of interest.

\section{References}

1. Kolb H, Mandrup-Poulsen T. The global diabetes epidemic as a consequence of lifestyle-induced low-grade inflammation. Diabetologia. 2010;53(1):10-20.

2. Shaw AS, Sicree RA, Zimmet PZ. Global estimates of the prevalence of diabetes for 2010 and 2030. Diabetes Res Clin Pract. 2010;87(1):4-14.

3. Kolb H, Mandrup-Poulsen T. An immune origin of type 2 diabetes? Diabetologia. 2005;48(6):1038-1050.

4. Moller DE. Potential role of TNF - alpha in the pathogenesis of insulin resistance and type 2 diabetes. Trends Endocrinol Metab. 2000;11(6):212-217

5. IIIig T, Bongardt F, Schopfer-Wendels A, et al. Genetics of type 2 diabetes: impact of interleukin- 6 gene variants. Gesundheitswesen 2005;67(Suppl 1):S122-126.

6. $\mathrm{Hu} \mathrm{FB}$, Meigs JB, Li TY, et al. Inflammatory markers and risk of developing type 2 diabetes in women. Diabetes. 2004;53(3):693-700.

7. Kristiansen OP, Mandrup-Poulsen T. Interleukin 6 and Diabetes- the Good, the bad, or the indifferent? Diabetes. 2005;54(Suppl 2):S114 S124.

8. Carey AL, Bruce CR, Sacchetti M, et al. Interlerleukin-6 and tumor necrosis factor-alpha are not increased in patients with Type 2 diabetes: evidence that plasma interleukin-6 is related to fat mass and not insulin responsiveness. Diabetologia. 2004;47(6):1029-1037.

9. Hotamisligil GS, Arner P, Caro JF, et al. Increased adipose tissue expression of tumor necrosis factor-alpha in human obesity and insulin resistance. J Clin Invest. 1995;95(5):2409-2415.

10. Hoene M, Weigert C. The Role of interleukin-6 in insulin resistance, body fat distribution and energy balance. Obes Rev. 2008;9(1):20-29.
11. Glunds S, Krook A. Role of interleukin-6 signaling in glucose and lipid metabolism. Acta Physiol (Oxf). 2008;192(1):37-48.

12. Lorenzo M, Fernandez-Veledo S, Villa-Bedmar R, et al. Insulin resistance induced by tumor necrosis factor-alpha in myocytes and brown adipocytes. J Anim Sci. 2008;86(14 Suppl):E94-E104.

13. Ruge T, Lockton JA, Renstrom F, et al. Acute hyperinsulinism raises plasma interleukin- 6 in both non diabetic and type 2 diabetes mellitus subjects, and this effect is inversely associated with body mass index. Metabolism. 2009;58(6):860-866.

14. Buschard K, Aaen K, Horn T, et al. Interleukin 6: a functional and structural in vitro modulator of beta-cells from islets of Langerhans. Autoimmunity. 1990;5(3):185-194.

15. Ortis F, Pirot P, Naamane N, et al. Induction of nuclear factor-kappa B and its down regulation genes by TNF-alpha and IL-1beta has a pro-apoptic role in pancreatic beta cells. Diabetologia. 2008;51(7):1213-1225.

16. Sookian SC, Gonzalez C, Pirola CJ. Meta-analysis on the G308A tumor necrosis alpha gene variant and phenotypes associated with the metabolic syndrome. Obes Res. 2005;13(12):2122-2131.

17. Kubaszek A, Pihlajamaki J, Punnonen K, et al. The C-174G promoter polymorphism of the IL-6 gene affects energy expenditure and insulin sensitivity. Diabetes. 2003;52(2):558-561.

18. Yamashina M, Kaneko Y, Maesawa C, et al. Association of TNF-alpha gene promoter $\mathrm{C}-857 \mathrm{~T}$ polymorphism with higher serum LDL cholesterol levels and carotid plaque formation in Japanese patients with type 2 diabetes. Tohoku J Exp Med. 2007;211(3):251-258.

19. Heijmans BT, Westendorp RG, Droog S, et al. Association of the tumour necrosis factor alpha $-308 \mathrm{G} /$ A polymorphism with the risk of diabetes in an elderly population - based cohort. Genes Immun. 2002;3(4):225-228.

20. Kubaszek A, Pihlajamäki J, Komarovski V, et al. Promoter polymorphism of the TNF-alpha (G-308A) and IL-6 (C-174G) genes predict the conversion from impaired glucose tolerance to type 2 diabetes: the Finnish Diabetes Prevention Study. Diabetes. 2003;52(7):1872-1876.

21. Hamman A, Mantzora C, Vidal-Puig A, et al. Genetic variability in the TNF-alpha promoter is not associated with type II diabetes mellitus (NIDDM). Biochem Biophys Res Commun. 1995;211(3):833-839.

22. Tsiavou A, Hatziagelaki E, Chaidaroglou A, et al. TNF-alpha, TGFbeta 1, IL-10, IL-6, gene polymorphism in latent autoimmune diabetes of adults (LADA) and type 2 diabetes mellitus. $J$ Clin Immunol. 2004;24(6):591-599.

23. Li H, Groop L, Nilsson A, et al. A combination of human leukocyte antigen DQB1*02 and the tumor necrosis factor-alpha promoter G3081 polymorphism predisposes to an insulin-deficient phenotype in patients with type 2 diabetes. J Clin Endocrinol Metab. 2003;88(6):2767-2774.

24. Fang Q, Xiang K, Lu J. The mechanism of tumor necrosis factor-alpha (TNF-alpha) induced insulin resistance by variation in promoter region of TNF-alpha gene. Zhonghua YI Xue Za Zhi. 1999;79(5):343-345.

25. Liu HL, Lin YG, Wu J, et al. Impact of genetic polymorphisms of leptin and TNF-alpha on rosiglitazone response in Chinese patients with type 2 diabetes. Eur J Clin Pharmacol. 2008;64(7):663-671.

26. Kim HR, Lee MK, Park AJ. The -308 and -238 polymorphisms of the TNF-alpha promoter gene in type 2 diabetes mellitus. Korean J Lab Med. 2006;26(1):58-63.

27. Zeggini E, Groves CJ, Parkinson JR, et al. Large-scale studies of the association between variation at the TNF/LDA locus and susceptibility to type 2 diabetes. Diabetologia. 2005;48(10):2013-2017.

28. Shiau MY, Wu CY, Huang CN, et al. TNF-alpha polymorphisms and type 2 diabetes mellitus in Taiwanese patients. Tissue Antigens. 2003;61(5):393-397. 
29. Furuta M, Yano Y, Ito K, et al. Relationship of the tumor necrosis factoralpha $-308 \mathrm{~A} / \mathrm{G}$ promoter polymorphism with insulin sensitivity and abdominal fat distribution in Japanese patients with type 2 diabetes mellitus. Diabetes Res Clin Pract. 2002;56(2):141-145.

30. Rasmussen SK, Urhammer SA, Jensen JN, et al. The -238 and -308 $\mathrm{G} \rightarrow \mathrm{A}$ polymorphisms of the tumor necrosis factor alpha gene promoter are not associated with features of the insulin resistance syndrome or altered birth weight in Danish Caucasians. Diabetes Res Clin Pract. 2000;54(2):89-94

31. Morris AM, Heilbronn LK, Noakes M, et al. -308 Nco 1 polymorphism of tumour necrosis factor alpha in overweight Caucasians. Diabetes Res Clin Pract. 2003;62(3):197-201.

32. Bouhaha R, Baroudi T, Enaffaa H, et al. Study of TNF alpha -308G/A and IL6 -174G/C polymorphism in type 2 diabetes and obesity risk in the Tunisian population. Clin Biochem. 2010;43(6):549-552.

33. Feng RN, Zhao C, Sun CH et al. Meta-analysis of TNF-308 G/A polymorphism and type 2 diabetes mellitus. PLoS One. 2011;6(4):e18480.

34. Kolla VK, Madhavi G, Pulla-Reddy V, et al. Association of tumor necrosis factor alpha, interferon gamma and interleukin 10 gene polymorphism with peripheral neuropathy in South Indian patients with type 2 diabetes. Cytokine. 2009;47(3):173-177.

35. Bhagat N, Agrawal M, Luthra K, et al. Evaluation of single nucleotide polymorphism of Pro12Ala in peroxisome proliferator-activated receptor $-\gamma$ and Gly308Ala in tumor necrosis factor- $\alpha$ genes in obese Asian Indians: a population-based study. Diabetes, Metabolic Syndrome and Obesity: Targets and Therapy. 2010;3:349-356.

36. Wilson AG, Symons JA, McDowell TL, et al. Effects of a polymorphism in the human tumor necrosis factor alpha promoter on transcriptional activation. Proc Natl Acad Sci USA. 1997;94(7):3195-3199.

37. Kroeger KM, Carwille KS, Abraham LJ. The -308 tumor necrosis factoralpha promoter polymorphism effects transcription. Mol Immunol. 1997;34(5):391-399.

38. Louis E, Franchimont D, Piron A, et al. Tumor necrosis factor (TNF) gene polymorphism influences TNF-alpha production in lipopolysaccharide (LPS) - stimulated more blood cell culture in healthy humans. Clin EXP Immunol. 1998;113(3):401-406.

39. Wang Y, Ng MC, So WY, et al. Association between tumour necrosis factor-alpha G308A polymorphism and risk of nephropathy in obese Chinese type 2 diabetic patients. Nephrol Dial Transplant. 2005;20(12):2733-2738.

40. Kankova K, Marova I Jansen EH, Vasků A, et al. Polymorphism Nco in tumor necrosis factor B is associated with fasting glycemia and lipid parameters in healthy non-obese Caucasian subjects. Diabetes Metab. 2002;28(3):231-237.

41. Sheu WH, Wu CY, Huang CN. Tissue necrosis factor alpha-238 and-308 polymorphisms do not associate with insulin resistance in hypertensive subjects. Metabolism 2003;50:1447-1451.

42. Fernandez-Real JM, Gutierrez C, Ricart W. The TNF-alpha gene Nco I polymorphism influences the relationship among insulin resistance, percent body fat, and increased serum leptin levels. Diabetes. 1997;46(9):1468-1472.

43. Wybranska I, Malczewska-Malec M, Niedbal S, et al. The TNF-alpha gene Ncol polymorphism at position -308 of the promoter influences insulin resistance and increased serum triglycerides after postprandial lipaemia in familial obesity. Clin Chem Lab Med. 2003;41(4):501-510.

44. Fontaine-Bisson B, Wolever TM, ChiassonJL, et al. Tumor necrosis factor alpha $-238 \mathrm{G}>\mathrm{A}$ genotype alters postprandial plasma levels of free fatty acids in obese individuals with type 2 diabetes mellitus. Metabolism. 2007;56(5):649-655.
45. Dalziel B, Gosby AK, Richman RM, et al. Association of the TNF-alpha -308 G/A promoter polymorphism with insulin resistance in obesity. Obes Res. 2002;10(5):401-407.

46. Milner CR, Craig JE, Hussey ND, et al. No association between the -308 polymorphism in the tumour necrosis factor alpha (TNF alpha) promoter region and polycystic ovaries. Mol Hum Reprod. 1999;5(1):5-9.

47. Ishii T, Hirose H, Saito I, et al. Tumor necrosis factor alpha gene G-308A polymorphism, insulin resistance and fasting plasma glucose in young, older and diabetic Japanese men. Metabolism. 2000;49(12):1616-1618.

48. Walston J, Seibert M, Yen CJ, et al. Tumor necrosis factor-alpha -238 and -308 polymorphisms do not associated with traits related to obesity and insulin resistance. Diabetes. 1999;48:2096-2098.

49. Koch M, Rett K, Volk A. The tumor necrosis factor alpha $-238 \mathrm{G} \rightarrow \mathrm{A}$ and $-308 \mathrm{G} \rightarrow \mathrm{A}$ promoter polymorphisms are not associated with insulin sensitivity and insulin secretion in young healthy relatives of type II diabetic patients. Diabetologia. 2000;43(2):181-184.

50. Lee SC, $\mathrm{Pu} \mathrm{YB}$, Thomas GN, et al. Tumor necrosis factor-alpha gene G-308A polymorphism in the metabolic syndrome. Metabolism. 2000;49(8):1021-1024.

51. Romeo S, Sentinelli F, Capici F, et al. The G-308A variant of the tumor necrosis factor-alpha (TNF-alpha) gene is not associated with obesity, insulin resistance and body fat distribution. BMC Med Genet. 2001;2:10.

52. Day CP, Grove J, Daly AK, et al. Tumour necrosis factor alpha gene promoter polymorphism and decreased insulin resistance. Diabetologia. 1998;41(4):430-434.

53. Pihlajamaki J, Ylinen M, Karhappa P, et al. The effect of the -308A allele of the TNF-alpha gene on insulin action is dependent on obesity. Obes Res. 2003;11(7):912-917.

54. Herrmann SM, Ricard S, Nicaud V, et al. Polymorphisms of the tumor necrosis factor alpha gene, coronary heart disease and obesity. Eur J Clin Invest. 1998;28(1):59-66.

55. Brand E, Schorr U, Kunz I, et al. Tumor necrosis factor-alpha -308 G/A polymorphism in obese Caucasians. Int $J$ Obes Relat Metab Disord. 2001;25(4):581-585

56. Hoffstedt J, Erikson P, Hallstrom L, et al. Excessive fat accumulation is associated with the TNF alpha-308 G/A promoter polymorphism in women, but not in men. Diabetologia. 2000;43(1):117-120.

57. Corbalan NS, Marti A, Forga L, et al. Influence of two polymorphisms of the tumor necrosis factor-alpha gene on the obesity phenotype. Diabetes Nutr Metab. 2004;17(1):17-22.

58. Ishii T, Hirose H, Saito I, et al. Tumor necrosis factor alpha gene G-308A polymorphism, insulin resistance and fasting plasma glucose in young, older and diabetic Japanese men. Metabolism. 2000;49(12):1616-1618.

59. Santos M JL, Patino GA, Angel BB, et al. Association between tumor necrosis factor-alpha promoter polymorphisms and type 2 diabetes and obesity in Chilean elderly women. Rev Med Chil. 2006;134(9):1099-1116.

60. Chouchane L, Danguir J, Beji C, et al. Genetic variation in the stress protein hsp 70-2 gene is highly associated with obesity. Int J Obes Relat Metab Disord. 2001;25(4):462-466.

61. Hawrami K, Hitman GA, Rema M, et al. Association in non-insulin dependent diabetes mellitus subjects between susceptibility to retinopathy and tumor necrosis factor polymorphism. Hum Immunol. 1996;46(1):49-64. 